\title{
Epoxy Resins and their Zinc Composites as Novel Anti- Corrosive Materials for Copper in 3\% Sodium Chloride Solution: Experimental and Computational Studies ${ }^{\dagger}$
}

\author{
Omar Dagdag ${ }^{1, *}$, Zaki Safi ${ }^{2}$, Chandrabhan Verma ${ }^{3, *}$, E. E. Ebenso ${ }^{4,5,6}$, Nuha Wazzan ${ }^{7}$, Mustapha El \\ Gouri ${ }^{1}$
}

1 Laboratory of Industrial Technologies and Services (LITS), Department of Process Engineering, Height School of Technology, Sidi Mohammed Ben Abdallah University, P.O. Box 2427, 30000, Fes, Morocco; omar.dagdag@uit.ac.ma (O.D.); mustapha.elgouri@usmba.ac.ma (M.E.G.);

2 Al Azhar University-Gaza, Chemistry Department, Faculty of Science, P.O Box 1277, Gaza, Palestine; zaki.safi@gmail.com (Z.S.);

3 Center of Research Excellence in Corrosion, Research Institute, King Fahd University of Petroleum and Minerals, Dhahran 31261, Saudi Arabia; chanraverma.rs.apc@itbhu.ac.in (C.V.);

4 Materials Science Innovation and Modelling (MaSIM) Research Focus Area, Faculty of Natural and Agricultural Sciences, North-West University (Mafikeng Campus), Private Bag X2046, Mmabatho 2735, South Africa; Eno.Ebenso@ nwu.ac.za (E.E.E.);

5 Department of Chemistry, College of Science, Engineering and Technology, University of South Africa, Florida, Roodepoort 1710, South Africa; Eno.Ebenso@nwu.ac.za (E.E.E.);

6 Nanotechnology and Water Sustainability Research Unit, College of Science, Engineering and Technology, University of South Africa, Johannesburg 1709, South Africa; Eno.Ebenso@nwu.ac.za (E.E.E.);

7 King Abdulaziz University, Chemistry Department, Faculty of Science, P.O Box 42805, Jeddah, 21589, Saudi Arabia; nwazzan@kau.edu.sa (N.W.);

* Correspondence: omar.dagdag@uit.ac.ma; chanraverma.rs.apc@itbhu.ac.in;

$\dagger$ Presented at Materials Chemistry and Physics (Materials Chemistry 2020) - International e-Conference

Received: 16.09.2020; Revised: 20.09.2020; Accepted: 24.09.2020; Published: 27.09.2020

Abstract: The evaluation the anticorrosive performance of two macromolecular aromatic epoxy resins (ERs), namely, tetra glycidyl of ethylene dianiline (TGEDA), hexaglycidyl Tris (p-Ethylene Dianiline) Phosphoric Triamide (HGEDPAT), and their polymer composite reinforced with Zinc for copper corrosion in $3 \% \mathrm{NaCl}$ by means of computational and experimental analyses. Anticorrosive property of the standards and composites was demonstrated using experimental and computational methods. Electrochemical results showed that HGEDAPT cured with methylene dianiline (MDA) showed better protection efficiency with optimum corrosion current density (icorr) value of $2.0 \mu \mathrm{cm}^{-2}$ and the polarization resistance $\left(R_{\mathrm{p}}\right)$ value of $17,00 \mathrm{k} \Omega . \mathrm{cm}^{2}$ than that of TGEDA-MDA having icorr value of 2.4 $\mu \mathrm{cm}^{-2}$ and the $R_{\mathrm{p}}$ value of $15.24 \mathrm{k} \Omega . \mathrm{cm}^{2}$. The anticorrosive effect of TGEDA-MDA and HGEDAPTMDA was evaluated in the presence of 5\% zinc ( $\mathrm{Zn})$. Experimental results demonstrate that the presence of 5\% of zinc in TGEDA-MDA and HGEDAPT-MDA formulations significantly enhanced their protection ability. The anticorrosive effect of different formulations followed the order: ER1 (TGEDAMDA) (potentiodynamic polarization (PDP); $90 \%$ and electrochemical impedance spectroscopy (EIS) 92\%) < ER2 (HGEDAPT-MDA) (PDP; 92\% and EIS 93\%) < ER3 (TGEDA-MDA-5\%Zn) (PDP; 96\% and EIS 97\%) < ER4 (HGEDAPT-MDA-5\%Zn) (PDP; 97\% and EIS 98.5\%). Density Functional Theory (DFT) study revealed that ER1 and ER2 interact with the metallic surface using donor-acceptor interactions in which electron-rich centers acted as the most favorable sites for the interactions. Molecular dynamics (MD) simulations studies suggest that ER1 and ER2 acquire flat or horizontal orientations, and their orientations on the metallic surface are largely influenced by the presence of zinc. Different experimental and computational studies are in good agreement. 
Keywords: polymer composite; anticorrosive composite materials; zinc composite; copper; $3 \% \mathrm{NaCl}$; computational simulations.

(C) 2020 by the authors. This article is an open-access article distributed under the terms and conditions of the Creative Commons Attribution (CC BY) license (https://creativecommons.org/licenses/by/4.0/).

\section{Funding}

This research received no external funding.

\section{Acknowledgments}

Nuha Wazzan gratefully acknowledges King Abdulaziz University's High-Performance Computing Centre (Aziz Supercomputer) (http://hpc.kau.edu.sa) for assisting with the calculations for this study. This research was partially supported by the National Natural Science Foundation of China (21706195).

\section{Conflicts of Interest}

The authors declare no conflict of interest. 